\title{
Experimental performance analysis of LPG four wheeler engines
}

\author{
R. R. Saraf ${ }^{1}$, S. S. Thipse ${ }^{2} \&$ P. K. Saxena ${ }^{1}$ \\ ${ }^{1}$ Malviya National Institute of Technology, Jaipur, India \\ ${ }^{2}$ Automotive Research Association of India, Pune, India
}

\begin{abstract}
This paper presents experimental performance analysis of four wheeler Liquified Petroleum Gas (LPG) car engines with different specifications. In order to normalize the performance trends among different engines with different specifications viz. bore-to-stroke ratio, cubic capacity, compression ratio, a unit parameter, power per unit displacement $(\mathrm{Kw} / \mathrm{Lit})$ was defined and calculated for each of the engines. Analysis was made over eight sample engines of the same specifications and five sample engines of different specifications. The experimental test setup involves a state-of-the-art computer controlled and data acquisition system. The comparisons of performance trends among engines are presented. This work will be useful by engine designers and researchers to understand the general performance trend of LPG four wheeler engines.

Keywords: performance analysis, car engines, four wheeler, Liquefied Petroleum Gas (LPG).
\end{abstract}

\section{Introduction}

In the present scenario, the world is facing a crisis of environmental pollution and fuel depletion. In the past few years alternative fuels are being studied by researchers as viable alternative for transportation and passenger car vehicles. Alternative fuels have benefits like better fuel economy, less pollutants and abundance at lower cost. Liquefied petroleum gas (LPG) is recently been used in the Indian Car market, as it produces low exhaust emissions as compared to gasoline. It has other benefits like low cost and fuel economy.

Liquefied petroleum gas (LPG) is a by-product of natural gas processing and crude oil refining. It can consist of propane or butane or a mixture of both. LPG has the potential of producing lower $\mathrm{CO}$ and $\mathrm{HC}$ emissions due to its simple 
chemical composition and complete combustion. It has a higher octane rating, which enables a higher compression ratio to be employed, and hence gives more thermal efficiency. LPG engines have good durability and better cold start performance. Power output in a LPG engine is less by about 5 to $10 \%$ than a gasoline engine. A LPG system requires more safety. The volume of LPG required for combustion is more by 15 to $20 \%$ as compared to gasoline. LPG has a stoichiometric ratio of $15.6[1,2]$. In this experimental study, four-stroke cycle four cylinder, water-cooled, MPFI engines were tested as pert IS 14599 [3] and the results discussed. Engine speed was varied and different parameters were noted. A unit parameter power per unit displacement was calculated and was compared with other important parameters.

Specifications of the engine tested are as given below.

Engines, 8 in number, having similar specifications:

Type: Four-stroke cycle, Water Cooled SOHC, SI, MPFI

No. of cylinders: Four

Displacement: $1590 \mathrm{CC}$

Compression ratio: 9.0:1

Bore: $75 \mathrm{~mm}$

Stroke: $90 \mathrm{~mm}$

Engines, 5 in number, having different specifications.

1) Type: Four stroke cycle, 4 valves MPFI, SI engine

No. of cylinders: Four

Compression ratio: 9.0:1

Displacement: $1061 \mathrm{CC}$

Stroke: $72 \mathrm{~mm}$

Bore: $68.5 \mathrm{~mm}$

2) Type: Four stroke cycle, water cooled SOHC, MPFI, SI Engine

No. of cylinders: Four

Compression ratio: $9.4: 1$

Displacement: 1598 CC

Stroke: $81.5 \mathrm{~mm}$

Bore: $79.5 \mathrm{~mm}$

3) Type: Four stroke cycle 4 Valves MPFI, SI Engine

No. of cylinders: Four

Compression ratio: 9.0:1

Displacement: $1061 \mathrm{CC}$

Stroke: $72 \mathrm{~mm}$

Bore: $68.5 \mathrm{~mm}$

4) Type: Four stroke cycle, water cooled, MPFI, SI Engine

No. of cylinders: Four

Displacement: 1298 CC

Compression ratio: 9.0:1

Bore: $74 \mathrm{~mm}$

Stroke: $75.5 \mathrm{~mm}$

5) Type: four-stroke cycle, water-cooled, SOHC, MPFI, SI engine.

No. of cylinders: Four

Compression ratio: $9.4: 1$

Displacement: $1598 \mathrm{CC}$

Bore: $79 \mathrm{~mm}$

Stroke: $81.5 \mathrm{~mm}$

Fig. 1 shows the engine modification system for LPG operation. The LPG cylinder of capacity 40 to 60 lit supplies liquid LPG to a vaporizer, which is return-coolant, heated. Liquid LPG is vaporized and fuel in vapor form is supplied to a gas mixer. In the gas mixer air is mixed with fuel and supplied to the engine manifold. A fuel metering valve with a step motor is used to vary the quantity of fuel according to engine speed and load. The fuel shut off valve is 
used to stop and start the fuel supply. Air enters into the air fitter and filtered air goes to the mixer where it is mixed with fuel. The MAP sensor measures the manifold absolute pressure. It sends a signal to the Electronic Control Unit. An oxygen sensor is located in the exhaust, which measures oxygen in the exhaust and sends a signal to the ECU. The ECU calculates how much fuel is to be supplied and sends a signal to the fuel metering valve. The RPM sensor measures the speed and sends a signal to the ECU. The ECU again decides the amount of fuel to be supplied and sends a signal accordingly to the fuel metering valve.

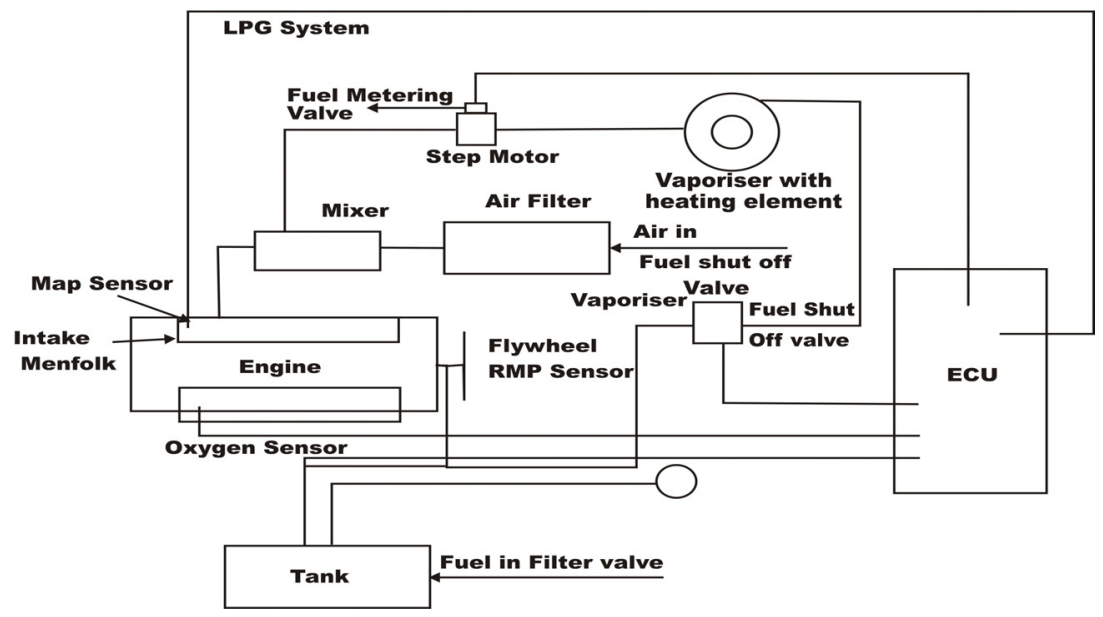

Figure 1: Engine modification system for LPG operation.

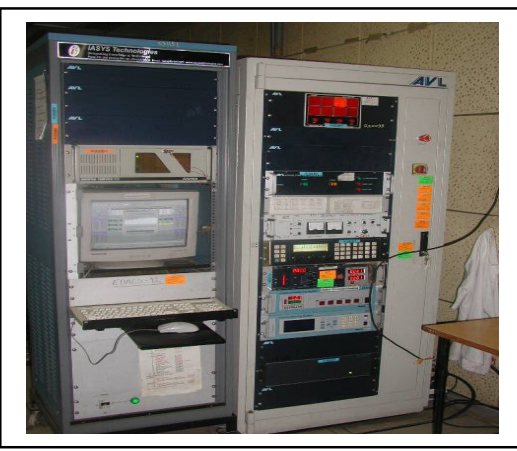

Figure 2: Computerized engine data acquisition and control system.

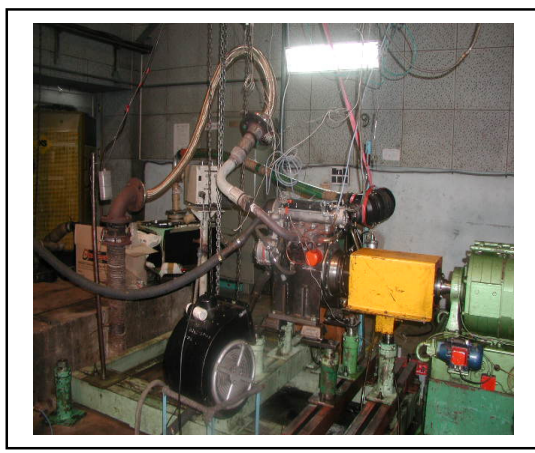

Figure 3: Experimental engine test setup. 


\section{Experimental set-up}

Figure 2 shows the experimental setup in the engine test room with the engine mounted on the test bench. Figure 3 shows the computerized data acquisition and control system used for engine testing. The AVL engine data acquisition and control system software automatically measures different engine parameters. It can be operated either in manual mode or automatic mode. It has an automatic test run sequence and on line formula definition. It has automatic test run capabilities, which enable the running of different types of tests by configuring the test set up. It has a programmable engine start or stop facility. The engine can be controlled either with the tolerance mode or without the tolerance mode. The system has automatic mode measurements and automatic mode recording as programmers like the alphanumeric display, XY - graph, Bar graph, slide and meter.

The PC based data acquisition system has a number of channels. All signals are conditioned and linearized in the PC and displayed in tabular form. Data collection and signal conditioning AT bus cards are provided with 8,12 or 16 bit resolution and can be selected as per the level of accuracy required. A snap shot record of all channels can be taken and written to disk every time the operator presses a particular key on the test cell keyboard. Each such record is time and date stamped and at any time the operator can call any data. The engine test bed has a stand for mounting the engine. An arrangement for different connections like the dynamometer, exhaust, fuel supply, and cooling water supply is provided. Sensors like the oxygen sensor, MAP sensor, temperature sensors, and pressure sensor are connected. These sensors measure different engine parameters and send signals to a computerized system where parameters are displayed. Three blowers were located at convenient positions in the test room, which blow air onto the engine to simulate actual driving condition.

\section{Experimental procedure}

The engines were tested as per the standard IS 14599. AVL, ALFA - 160, eddy current dynamometer was used for testing with a dynamometer constant of 19549.305.

The engine was mounted on the test bed and different sensors for measuring speed torque temperatures, pressures were connected to the sensor panel, which was located above the test engine. Three blowers were arranged in the test room which supply forced air onto the engine to simulate actual driving conditions. The engine was run and warmed up in accordance with the manufacturers recommendations. The engine was run at full throttle or full load conditions and performance data was obtained under stabilized operating conditions with an adequate fresh air supply to the engine. Different parameters like torque, speed and temperatures were recorded after they were maintained constantly for one minute. 


\section{Results and discussions}

\subsection{Results of testing a group of five engines}

A group of five engines was tested as per the Indian standard, IS14599, by using computerized data acquisition and a control system. A unit parameter power per unit displacement was calculated for each engine and other important parameters were compared with it. The rated torque was in the range of $70.36 \mathrm{Nm}$ to $111 \mathrm{Nm}$. The minimum temperature of exhaust gas was $560.3^{\circ} \mathrm{C}$ and the maximum temperature of exhaust gas was $802.1^{\circ} \mathrm{C}$. The exhaust gas temperature curve shows a hump in the middle. Kw/Lit was plotted with speed corresponding to maximum torque and speed corresponding to maximum power. The speed corresponding to maximum torque was in the range of 2850 RPM to 4000 RPM. Speeds corresponding to maximum torque were observed less than those corresponding to maximum power. The minimum value of speed corresponding to maximum power was observed 6010 RPM (Figs 4-7). The minimum value of the brake mean effective pressure was 6.86 bar and the maximum value of brake mean effective pressure was 7.78 bar. It was observed that brake mean effective pressure increases with an increase in the unit parameter Kw/Lit. Curve fitting [4] has been done by using the method of least squares.

Table 1.

\begin{tabular}{|c|c|c|c|}
\hline Kw/lit & T rated & Kw/lit & $\begin{array}{c}\text { T-exh } \\
\text { gas }\end{array}$ \\
\hline 31.1264 & 102.06 & 31.1264 & 802.1 \\
\hline 33.229 & 111.01 & 33.229 & 605.7 \\
\hline 34.1564 & 70.36 & 34.1564 & 758.2 \\
\hline 37.983 & 70.8 & 37.983 & 777.8 \\
\hline 38.906 & 98.81 & 38.906 & 560.3 \\
\hline
\end{tabular}

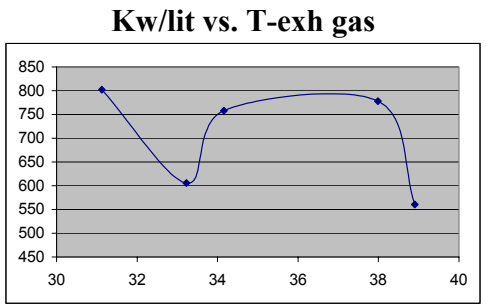

Figure 4: Graph showing relation between $\mathrm{KW} /$ Lit and maximum temperature of exhaust gas.
Table 2 .

\begin{tabular}{|c|c|c|c|}
\hline Kw/lit & RPM-T & Kw/lit & RPM-P \\
\hline 31.1264 & 3350 & 31.1264 & 5450 \\
\hline 33.229 & 3055 & 33.229 & 5505 \\
\hline 34.1564 & 4000 & 34.1564 & 6005 \\
\hline 37.983 & 4000 & 37.983 & 6010 \\
\hline 38.906 & 2850 & 38.906 & 6000 \\
\hline
\end{tabular}

Kw/lit vs. Rpm-T

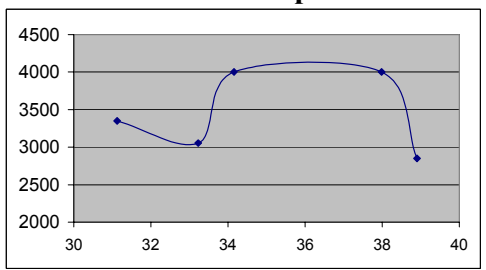

Figure 5: Graph showing relation between KW/Lit and speed corresponding to maximum torque. 
Kw/lit vs. T-rated

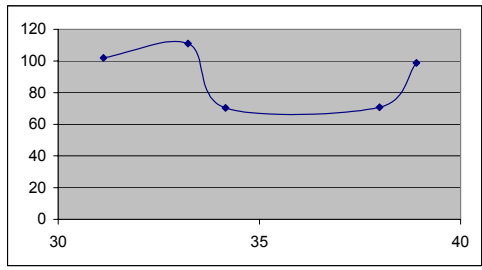

Figure 6: Graph showing relation between $\mathrm{KW} / \mathrm{Lit}$ and rated torque.
Kw/lit vs. Rpm-P

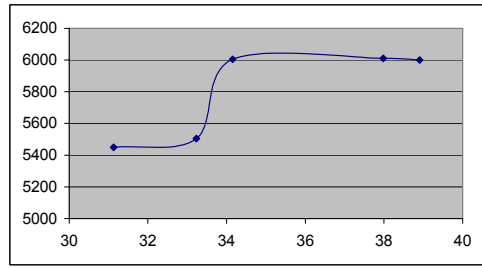

Figure 7: Graph showing relation between $\mathrm{KW} /$ Lit and speed corresponding to maximum power.

\subsection{Results of testing a group of eight engines}

Another group of eight engines was tested. A unit parameter $\mathrm{Kw} / \mathrm{Lit}$ was calculated and was compared with the maximum temperature of exhaust gas for each engine. The maximum temperature of exhaust gas was $915.6^{\circ} \mathrm{C}$. The maximum value of rated torque was $125.13 \mathrm{Nm}$ and the minimum value of rated torque was 104-39 $\mathrm{Nm}$. It was observed that the minimum value of unit parameter Kw/Lit was 32.32 and the maximum value was 38.415.

Power per unit displacement was compared with speed corresponding to maximum torque and speed corresponding to maximum power. Maximum speed corresponding to maximum torque was 4500 RPM and minimum speed corresponding to maximum torque was 2800 RPM. Speed corresponding to maximum power is higher than speed corresponding to maximum torque. The minimum value of speed corresponding to maximum power is 5010 RPM and the maximum value for the same is 5510 RPM (Figs 8-11).

Table 3.

\begin{tabular}{|c|c|c|c|}
\hline $\boldsymbol{K} \boldsymbol{w}$ /lit & RPM-T & Kw/lit & RPM-P \\
\hline 32.32 & 2855 & 32.32 & 5510 \\
\hline 32.4088 & 4500 & 32.4088 & 5505 \\
\hline 32.635 & 2855 & 32.635 & 5010 \\
\hline 35.7735 & 2850 & 35.7735 & 5505 \\
\hline 35.8176 & 2800 & 35.8176 & 5205 \\
\hline 35.8427 & 2850 & 35.8427 & 5500 \\
\hline 36.2578 & 3200 & 36.2578 & 5205 \\
\hline 38.415 & 3000 & 38.415 & 5500 \\
\hline
\end{tabular}

Table 4.

\begin{tabular}{|c|c|c|c|}
\hline Kw/lit & $\begin{array}{c}\text { T-exh } \\
\text { gas }\end{array}$ & Kw/lit & T-rated \\
\hline 32.32 & 890.8 & 32.32 & 118.35 \\
\hline 32.4088 & 710 & 32.4088 & 104.39 \\
\hline 32.635 & 860.6 & 32.635 & 111.93 \\
\hline 35.77358 & 784.1 & 35.77358 & 125.13 \\
\hline 35.8176 & 865.9 & 35.8176 & 119.07 \\
\hline 35.84276 & 915.6 & 35.84276 & 115.55 \\
\hline 36.25786 & 848.8 & 36.25786 & 116.12 \\
\hline 38.415 & 824.3 & 38.415 & 120.68 \\
\hline
\end{tabular}


Kw/lit vs. RMP-T

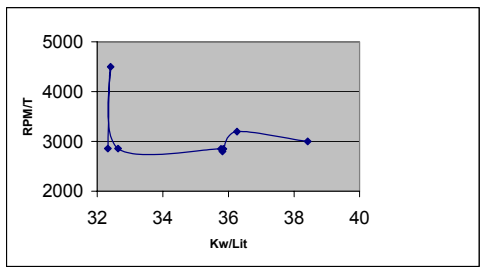

Figure 8: Graph showing relation between $\mathrm{KW} / \mathrm{Lit}$ and speed corresponding to maximum torque.

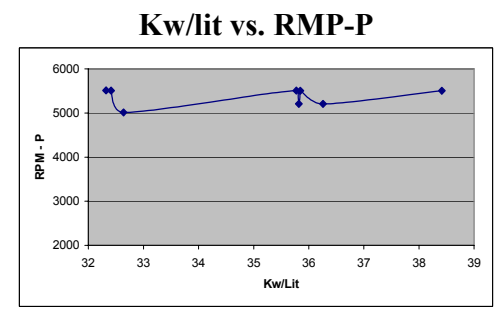

Figure 10: Graph showing relation between $\mathrm{KW} / \mathrm{Lit}$ and speed corresponding to maximum power.
Kw/lit vs. T- exh gas

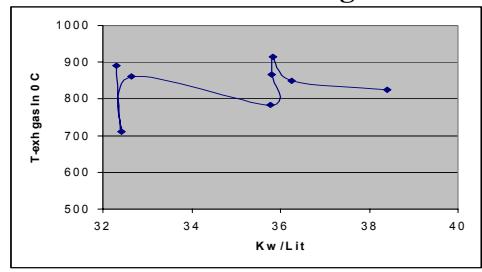

Figure 9: Graph showing relation between $\mathrm{KW} / \mathrm{Lit}$ and maximum temperature of exhaust gas.

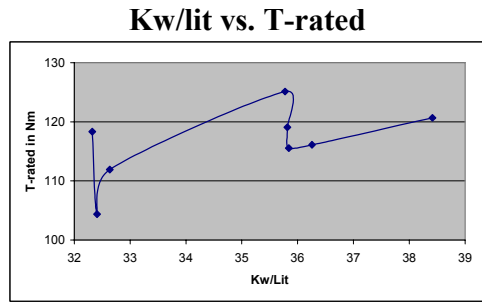

Figure 11: Graph showing relation between $\mathrm{KW} / \mathrm{Lit}$ and rated torque.

\subsection{Results of testing one sample engine from group of eight engines}

The performance characteristics of one sample engine are also shown in Figs 12-18. As engine speed increases power increases. The maximum power developed was $57.65 \mathrm{~kW}$ at 5205 RPM. The minimum power developed was $29.14 \mathrm{kw}$ at 2500 RPM. The torque curve shows a decreasing trend with an increase in engine speed. The torque is inversely proportional to speed. The maximum value of torque developed was $116.12 \mathrm{Nm}$ at $3200 \mathrm{RPM}$ and the minimum value of torque developed was $96.25 \mathrm{Nm}$ at $5705 \mathrm{RPM}$. The temperature of exhaust gas increases with engine speed. The maximum temperature of exhaust gas was $848.8^{\circ} \mathrm{C}$ and the minimum temperature of exhaust gas was $695.7^{\circ} \mathrm{C}$. The maximum value of lube oil temperature was $124.3^{\circ} \mathrm{C}$ and the minimum value of lube oil temperature was $80.9^{\circ} \mathrm{C}$. The in take air temperature curve shows an increasing trend with an increase in engine 
speed. Graphs of speed verses temperature of water show the decreasing and increasing trend with increases in engine speed. The brake mean effective pressure was calculated and plotted against engine speed. It shows a decreasing trend as engine speed increases. The maximum value of brake mean effective pressure was 9.1814 bar and the minimum value of brake mean effective pressure was 9.058 bar.

Table 5.

\begin{tabular}{|c|c|c|c|}
\hline $\begin{array}{l}\text { Eng } \\
\text { speed }\end{array}$ & Torque & $\begin{array}{l}\text { Eng } \\
\text { speed }\end{array}$ & Power \\
\hline 2500 & 111.13 & 2500 & 29.14 \\
\hline 2800 & 114.69 & 2800 & 33.6 \\
\hline 3000 & 113.83 & 3000 & 35.79 \\
\hline 3200 & 116.12 & 3200 & 38.92 \\
\hline 3500 & 112.81 & 3500 & 41.36 \\
\hline 4000 & 109.84 & 4000 & 46.02 \\
\hline 4200 & 111.25 & 4200 & 48.95 \\
\hline 4555 & 110.02 & 4555 & 52.47 \\
\hline 4805 & 109.02 & 4805 & 54.87 \\
\hline 5205 & 105.73 & 5205 & 57.65 \\
\hline 5505 & 99.63 & 5505 & 57.45 \\
\hline 5705 & 96.25 & 5705 & 57.52 \\
\hline
\end{tabular}

Speed Vs Torque

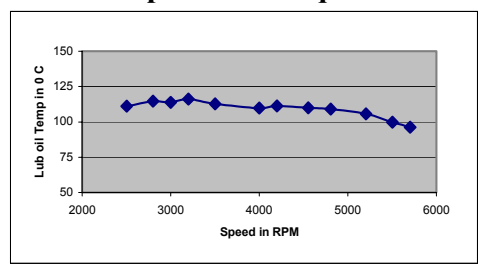

Figure 12: Graph showing relation between speed and torque.

\section{Speed vs. Power}

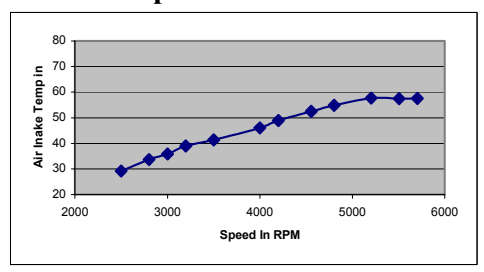

Figure 14: Graph showing relation between speed and power.
Table 6.

\begin{tabular}{|c|c|c|c|}
\hline $\begin{array}{l}\text { Eng } \\
\text { speed }\end{array}$ & $\begin{array}{c}\text { Exh } \\
\text { gas T }\end{array}$ & $\begin{array}{l}\text { Eng } \\
\text { speed }\end{array}$ & $\begin{array}{c}\text { T-Lub } \\
\text { oil }\end{array}$ \\
\hline 2500 & 695.7 & 2500 & 80.9 \\
\hline 2800 & 707.4 & 2800 & 83.3 \\
\hline 3000 & 716.2 & 3000 & 85.4 \\
\hline 3200 & 710.6 & 3200 & 88.5 \\
\hline 3500 & 718 & 3500 & 92.2 \\
\hline 4000 & 754.2 & 4000 & 96.6 \\
\hline 4200 & 777.5 & 4200 & 99.7 \\
\hline 4555 & 803.1 & 4555 & 104.4 \\
\hline 4805 & 818.5 & 4805 & 108.3 \\
\hline 5205 & 830.7 & 5205 & 113.1 \\
\hline 5505 & 839.3 & 5505 & 118.4 \\
\hline 5705 & 848.8 & 5705 & 124.3 \\
\hline
\end{tabular}

Speed vs. T-exh gas

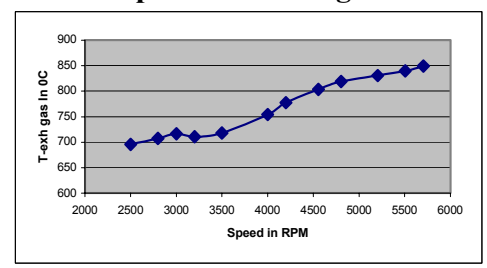

Figure 13: Graph showing relation between speed and temperature of exhaust gas.

Speed vs. T-lube oil

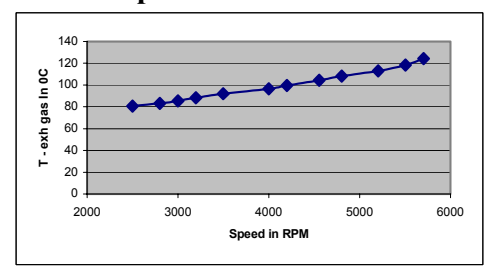

Figure 15: Graph showing relation between Speed and temperature of lub oil. 
Table 7.

\begin{tabular}{|l|c|c|c|}
\hline $\begin{array}{l}\text { Eng } \\
\text { speed }\end{array}$ & AIT & $\begin{array}{l}\text { Eng } \\
\text { speed }\end{array}$ & $\begin{array}{l}\text { T- } \\
\text { Water }\end{array}$ \\
\hline 2500 & 21.8 & 2500 & 78 \\
\hline 2800 & 21.8 & 2800 & 77.9 \\
\hline 3000 & 21.8 & 3000 & 77.2 \\
\hline 3200 & 22.1 & 3200 & 87.2 \\
\hline 3500 & 22.1 & 3500 & 78.2 \\
\hline 4000 & 22.2 & 4000 & 78.3 \\
\hline 4200 & 22.2 & 4200 & 78.3 \\
\hline 4555 & 22.5 & 4555 & 78 \\
\hline 4805 & 23.1 & 4805 & 77.8 \\
\hline 5205 & 23.3 & 5205 & 78.7 \\
\hline 5505 & 23.2 & 5505 & 78.6 \\
\hline 5705 & 23.5 & 5705 & 78.4 \\
\hline
\end{tabular}

\section{Speed vs. Air Intake Temp}

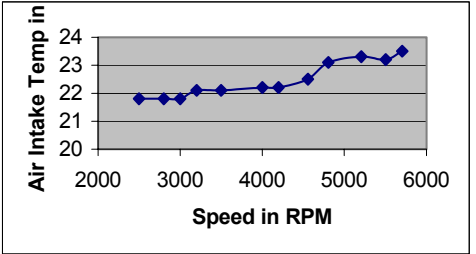

Figure 16: Graph showing relation between Speed and air intake temperature.
Table 8 .

\begin{tabular}{|l|c|}
\hline $\begin{array}{l}\text { Eng } \\
\text { speed }\end{array}$ & BMEP \\
\hline 2500 & 8.799 \\
\hline 2800 & 9.058 \\
\hline 3000 & 9.00589 \\
\hline 3200 & 9.1814 \\
\hline 3500 & 8.9207 \\
\hline 4000 & 8.685067 \\
\hline 4200 & 8.79812 \\
\hline 4555 & 8.69579 \\
\hline 4805 & 8.6204 \\
\hline 5205 & 8.361133 \\
\hline 5505 & 7.878 \\
\hline 5705 & 7.6111 \\
\hline
\end{tabular}

Speed vs. BMEP

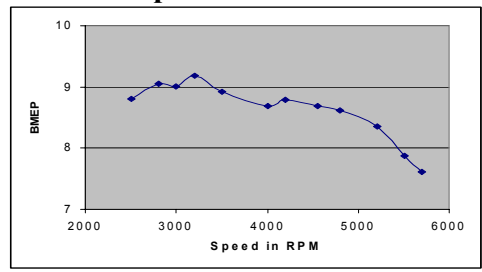

Figure 17: Graph showing relation between speed and BMEP.

Speed vs. T-water

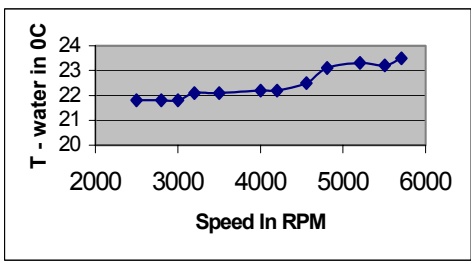

Figure 18: Graph showing relation between and temperature of cooling water.

\section{Conclusion}

Eight engines of the same specifications and five engines of different specifications were tested on a computerized data acquisition and control system by using LPG as the fuel and by using an engine modification system for LPG operation. A methodology was established to compare and contrast the performance of LPG four wheeler car engines at normalized conditions. A new 
normalized figure of merit has been defined which is suitable for performance comparison among car engines. The performance characteristic curves of one modern sample engine are shown. Curve fitting was done by using the method of least squares and the following equations are derived.

Curve fitting equations for group of eight engines:

For Kw/Lit vs. RPM-T

$y=6385.649708-93.66 x$

For Kw/Lit vs. T rated

$y=57.88+1.687 x$
For Kw/Lit vs. RPM-P

$\mathrm{y}=4911.4055+13.03828 \mathrm{x}$

For Kw/Lit vs. maximum temp. of exhaust gas

$y=686.598+4.32 x$

Curve fitting equations for group of five engines:

For Kw/Lit vs. RPM-T

$y=3514.291336-1.80482 x$

For Kw/Lit vs. maximum temp.

of exhaust gas

$\mathrm{y}=1182.573640-13.733 \mathrm{x}$
For Kw/Lit vs. RPM-P

$y=3250.604292+72.50272829 x$

For Kw/Lit vs. rated torque

$y=164.294-2.100 x$

Thus general performance trend is established for LPG engines by defining common Parameter, power per unit displacement (Kw/Lit). This enabled trend prediction and comparison of LPG engines with different specifications and different year of manufacture.

\section{Abbreviations}

PFI

ECU

LPG

T-rated

T-exhgas

RPM-T

RMP-P

$\mathrm{CO}$

$\mathrm{HC}$

T-lube oil

B.M.E.P.

AIT

T-Water

Eng. Speed
Port Fuel Injection

Electronic Control Unit

Liquefied Petroleum Gas

Rated Torque

Temperature of Exhaust Gas

Speed corresponding to maximum torque

Speed corresponding to maximum power

Carbon Monoxide

Hydrocarbon

Temperature of Lub oil

Brake mean effective pressure

Air Intake Temperature.

Temperature of cooling water

Engine Speed 
Urban Transport XIII: Urban Transport and the Environment in the 21st Century 521

\section{References}

[1] Poulton M.L. "Alternate Fuels for road vehicles" Computational Mechanics publications, Ashurst, Southampton, UK, 84-85, 94-95, 1990.

[2] Md. Ehsan, MSA Bhuriyan \& N. Naxmin, "Multifuel performance of a petrol engine for small scale power generation". SAE - 2003-32-0063 Society of automotive engineers 20034363, 2003.

[3] IS-14599-1999 "Performance requirements of positive and compression ignition engines", Indian standard institution, India, 1-15, 1999.

[4] Stoecker W.F., "Design of thermal systems" McGraw Hill Book Company, New York, Third edition 1989. 